\title{
REVIEW
}

\section{The genetics of tobacco use: methods, findings and policy implications}

\author{
W Hall, P Madden, M Lynskey
}

Tobacco Control 2002;11:119-124

Research on the genetics of smoking has increased our understanding of nicotine dependence, and it is likely to illuminate the mechanisms by which cigarette smoking adversely effects the health of smokers. Given recent advances in molecular biology, including the completion of the draft sequence of the human genome, interest has now turned to identifying gene markers that predict a heightened risk of using tobacco and developing nicotine dependence

$T$ hanks to RA Fisher, genetics has been linked to scepticism about a causal relation between cigarette smoking and lung cancer. ${ }^{12}$ Fisher $^{3}$ argued that the association between smoking and lung cancer was explained by shared genes that predisposed people to initiate smoking as young adults and to develop lung cancer in late adulthood. Much use was made of his hypothesis by the tobacco industry to manufacture a spurious controversy about the health effects of smoking, a fact that may have discouraged public health research into the genetic contribution to smoking. ${ }^{1}$

Over the past decade, research on the genetics of tobacco use has strongly suggested that genetic factors do play a role in different stages of tobacco use and dependence. Given the possible misuse and misunderstanding of this work, it is important for researchers and policy makers in the tobacco field to be acquainted with the research and its policy implications. Our aims are accordingly: (1) to summarise the results of recent research on the genetics of tobacco use from adoption, twin, linkage, and association studies; and (2) to consider the implications of these findings for public health and tobacco control policies.

\section{GENETIC STUDY DESIGNS AND RESEARCH FINDINGS}

See end of article for authors' affiliations

Correspondence to: Wayne Hall, Office of Public Policy and Ethics, Institute for Molecular

Bioscience, University of Queensland, St Lucia, Queensland 4072, Australia;

W.Hall@imb.uq.edu.au
Traditional family studies suggest that genetic factors influence smoking by reporting elevated rates of tobacco use and dependence in the relatives of people who smoke tobacco. For example, Niu and colleagues ${ }^{4}$ reported that individuals with a nicotine dependent sibling were 2.1-3.5 times more likely to be nicotine dependent (defined by Fagerstrom score and the revised tolerance questionnaire) than those who did not. Such studies, however, confound genetic and environmental influences because siblings share environmental influences as well as genes.
Specific study designs-adoption, twin, and linkage designs-are needed to separate the effects of genes from those of the environment.

\section{Adoption studies}

In the adoption design we compare the similarity in smoking between adoptive children and their biological parents with the similarity between adopted children and their adoptive parents or between adoptive sibling pairs and biological sibling pairs. If smoking is largely or wholly genetically determined, then there should be greater similarity between children and their biological parents and siblings than between adopted children and their adoptive parents or siblings. One early adoption study found an association between the smoking of foster children and their biological siblings but not their adoptive siblings. ${ }^{5}$ A recent adoption study ${ }^{6}$ reported moderate to strong associations between adoptees' smoking and that of their biological siblings, and between male adoptees' and their biological mothers' smoking.

It has become increasingly difficult to conduct adoption studies because fewer children are available for adoption except transnationally and there are ethical concerns about such studies. The older studies often lacked detailed information on biological parents and the placement of adoptees (usually to more advantaged homes) restricted variation in the environments to which they were exposed. Adoption studies also had a limited ability to assess the role of family environment because in some countries the practice was to match biological and adoptive parents on key demographic features (for example, education or religious affiliation), introducing a correlation between genes and environment. Finally, adoption studies that included subjects who were not adopted immediately at birth may have overestimated genetic effects by attributing the effects of early environmental exposures to genetic influences.

\section{Twin studies}

The twin study method compares the agreement in the behaviour of (1) monozygotic or identical twins who share the same genetic make-up, and (2) dizygotic or fraternal twins who share on average $50 \%$ of their genetic make up, the same as ordinary siblings. Twins are said to be "concordant" if both engage in the same behaviour (for example, both smoke tobacco). If certain assumptions are met (see below), a higher rate of agreement in monozygotic than dizygotic twins can be attributed to genetic factors. Statistical models estimate the percentage of variance in the trait 
Table 1 Estimates from twin studies of genetic $(A)$, shared environmental $(C)$, and non-shared environmental $(E)$ influences on smoking initiation and persistence in women and men

\begin{tabular}{|c|c|c|c|c|c|c|}
\hline & \multicolumn{3}{|c|}{ Women } & \multicolumn{3}{|c|}{ Men } \\
\hline & $A$ & $\mathrm{C}$ & $E$ & A & $\mathrm{C}$ & $E$ \\
\hline \multicolumn{7}{|l|}{ Initiation } \\
\hline Sweden 9 & 44 & 42 & 14 & 51 & 39 & 10 \\
\hline Denmark $^{10}$ & 79 & - & 21 & 84 & - & 16 \\
\hline Finland"1 & 37 & 50 & 13 & 50 & 33 & 17 \\
\hline Australia $^{12}$ & 77 & 4 & 19 & 28 & 43 & 29 \\
\hline Australia $^{13}$ & 60 & 26 & 14 & 80 & - & 20 \\
\hline USA second world war veterans ${ }^{14}$ & - & - & - & 59 & 21 & 20 \\
\hline USA Virginia ${ }^{12}$ & 84 & - & 16 & 84 & - & 16 \\
\hline USA Vietnam veterans ${ }^{15}$ & - & - & - & 39 & 49 & 12 \\
\hline \multicolumn{7}{|l|}{ Persistence } \\
\hline Sweden 9 & 59 & - & 41 & 52 & - & 48 \\
\hline Finland $^{16}$ & 71 & - & 29 & 68 & - & 32 \\
\hline Australia $^{17}$ & 53 & - & 47 & 53 & - & 47 \\
\hline Australia $^{13}$ & 62 & - & 38 & 62 & - & 38 \\
\hline USA $^{8}$ & 58 & - & 42 & 58 & - & 42 \\
\hline USA Vietnam veterans ${ }^{15}$ & - & - & - & 69 & - & 31 \\
\hline
\end{tabular}

that is explained by genes (heritability) and by shared (experiences shared by family members) and non-shared (experiences unique to the individual) environment.

The results of a number of large scale twin studies of cigarette smoking from around the world are summarised in table 1.9-17 The data presented in this table are the result of a re-analysis of data from the original studies. ${ }^{8}$ The top half of the table provides the results of eight studies that have examined genetic and environmental influences on smoking initiation; the bottom half summarises twin studies of smoking persistence.

Because the reported prevalence of smoking initiation was not high in these studies (all substantially lower than 90\%) we can assume that "smoking initiation" generally referred to the initiation of "regular", usually daily cigarette smoking. In fact, most of the Scandinavian studies of smoking initiation defined people who smoked less than 100 cigarettes in their lives as non-smokers. Despite the wide range of cultures, ages, and birth cohorts represented in these papers, estimates of the heritability of smoking initiation were substantial for both men and women: they ranged between $37 \%{ }^{11}$ and $84 \%{ }^{12}$ in women and between $28 \%{ }^{12}$ and $84 \%^{12}$ in men (see original papers for details). By contrast, there was little consistency between studies for the importance of family environment. In some studies, shared family environment was estimated to account for $50 \%{ }^{11}$ of the variance in smoking initiation among women and $49 \%{ }^{17}$ of the variance among men. Yet other studies $^{11}{ }^{12}$ reported no significant shared environmental influences on smoking initiation.

Findings from some ${ }^{815}{ }^{17}$ but not all studies of smoking persistence ${ }^{518}$ suggest that some genetic and environmental influences are specific to smoking persistence while there are some shared genetic and environmental influences on smoking persistence and smoking initiation. Analyses conducted by Madden and her colleagues ${ }^{19}$ suggest that the degree of overlap in genetic contribution to smoking initiation and persistence may vary with age and sex. Other studies have confirmed that both genetic and environmental influences play an important role in nicotine dependence. ${ }^{20-22}$

A critical assumption of the twin study method is that monozygotic and dizygotic twins have equal exposures to environmental influences that affect the trait under study (the "equal environments assumption"). If this assumption is not met (for example, because monozygotic twins have more similar environments than dizygotic twins), then twin studies provide inflated estimates of genetic influences on behaviour.
Research has generally, ${ }^{23-27}$ although not always, ${ }^{28}$ supported the validity of the equal environments assumption in studies of substance use. This has included studies of twin pairs who were misinformed about their zygosity ${ }^{23}{ }^{24}$ and retrospective reports of childhood and adult social environments in monozygotic and dizygotic twins. ${ }^{25-28}$

The traditional twin method also assumes that the environments of twins and singleton siblings are comparable. This assumption may not hold because twins have higher rates of obstetric complications and low birth weight than singleton births and there are different patterns of family and sibling interactions in families with twins than in those without. ${ }^{7}$

A final limitation of the twin study is that it has low statistical power to test for gene-environment interactions and gene-environment correlation effects in the aetiology of smoking and other behaviours. Some of these problems can be addressed using extensions of the twin design, including the study of the children of twins and other family members. ${ }^{7} 29$ For example, studies of the offspring of monozygotic twins who are discordant for smoking provide a powerful way of disentangling genetic and environmental effects because the offspring of the discordant monozygotic twins share the same genetic relationship to both twins but are exposed to different family environments. These designs have yet to be applied to the study of smoking behaviour and nicotine dependence.

\section{Studies of twins reared apart}

The study of twins reared apart is a powerful research design that combines aspects of twin and adoption studies. This design enables one to separate genetic effects from environmental effects because monozygotic twins reared apart share the same genes but different environments. Greater concordance in behaviour among monozygotic than dizygotic twins reared apart provides strong support for a genetic contribution to smoking.

There have been five studies of smoking in twins reared apart. ${ }^{30}{ }^{29-32}$ The most recent, and the most methodologically rigorous, ${ }^{32}$ concluded that $60 \%$ of the variance in regular tobacco use among men and among women born after 1940 could be explained by genetic factors. In women born earlier in the century, rates of regular tobacco use were substantially lower and modelling suggested that shared environmental effects largely accounted for twin resemblance in these women. 


\section{Summary of twin and adoption studies}

Despite the limitations in each of the experimental designs described above, there is strong support for genetic factors playing a role (along with environment) in tobacco smoking and nicotine dependence. This comes from the consistency of findings between twin studies and the convergence of results from the very different study designs. Given recent advances in molecular biology, including the completion of the draft sequence of the human genome, ${ }^{33}$ interest has now turned to identifying gene markers that predict a heightened risk of using tobacco and developing nicotine dependence.

\section{Linkage studies}

A number of aspects of an individual's response to nicotine could have important effects on smoking. For example, individuals may vary in their sensitivity to nicotine's effects, the rate at which they develop tolerance to its effects, and in the severity of withdrawal symptoms if they stop smoking. These are likely to have a biological basis although this is as yet poorly understood. ${ }^{34}$

An important recent development has been the use of gene mapping methods to study tobacco use. Gene mapping identifies genes that predict a trait or disorder. The identification is empirical in that it is not based on prior knowledge of a gene's function, but is discovered by studying whether smoking is co-inherited with markers found in specific chromosomal regions. Positive reports of genetic linkage for alcohol related behaviours are beginning to emerge $e^{35-37}$ although as yet very few have been replicated.

Traditional methods of linkage analysis, which study co-inheritance within families ("pedigrees"), have been useful in mapping single gene dominant, recessive or $\mathrm{x}$ linked disorders. Typically large pedigrees containing multiple affected family members have been studied, sometimes over several generations. ${ }^{38}$ These studies test specific models for the inheritance of the disorder. It is difficult to use these traditional methods of linkage to study the genetics of smoking and other complex traits in which multiple genes probably play a role (that is, polygenic disorders and traits). In these cases, it has proven more difficult to replicate the genetic linkages than to find candidate regions of chromosomes. This is because the classical linkage method requires large pedigrees in which a single or, at most, only a few, risk increasing genes are assumed to be segregating. We also need to know (or guess) whether the genes involved in these disorders are having dominant, additive or recessive effects, which we typically do not know for complex behaviours such as smoking.

In studying the genetics of smoking it has become standard to use affected relative or allele sharing methods of analysis. ${ }^{39} 40$ These methods avoid the difficulty of defining "unaffected" individuals for complex behaviours such as smoking. It uses the nuclear family as the sampling unit to minimise the analytical problems that arise from the accumulation of multiple susceptibility genes in extended pedigrees. Typically, families with two or more affected siblings are identified, and the affected siblings and, whenever possible, both of their biological parents are genotyped. If a gene in a particular chromosomal region is associated with smoking, and if a genetic marker is in close proximity (that is, linked), then the affected siblings will be more likely to share the same maternal and/or paternal marker genes. In the absence of parental data there is a loss of statistical power ${ }^{41}$ that is only partially addressed by using multiple markers.

\section{Candidate genes for nicotine dependence}

There are a number of plausible "candidate genes" for nicotine dependence-that is, genes that affect an individual's vulnerability to developing nicotine dependence. These include polymorphism (variants of genes) that metabolise nicotine in ways that may reduce the likelihood of smoking (for example,
Pianezza and colleagues, ${ }^{42}$ but see Oscarson and associates ${ }^{43}$ for subsequent work suggesting that the original report was flawed because of genotyping errors). Another promising group of candidate genes code for dopamine receptors and transporters, ${ }^{44}{ }^{45}$ the neurotransmitter system that mediates reward in the nucleus acumbens of the midbrain. ${ }^{46}$ Studies have identified associations between smoking and some of these candidate genes, but for a number of reasons these associations have not been consistently replicated to date. ${ }^{46} 47$

The following factors contribute to the difficulty in finding reproducible associations between candidate genes and nicotine dependence. One is the multiple comparison problem: in searching for associations between smoking and a large number of candidate genes, there will be false positive associations. A second factor is heterogeneity between groups in the prevalence of these genes, something that may mask real associations and produce spurious ones in standard casecontrol comparisons. A third factor is that it is difficult to detect multiple genes of modest effect because association and linkage studies have low statistical power to detect these types of associations. ${ }^{48}{ }^{49}$ A fourth factor is differences between studies in the definition of a smoker. More work is necessary to identify measures that most adequately capture liability to tobacco use and nicotine dependence. These difficulties are not insurmountable so larger, better controlled studies of a smaller set of candidate genes will probably identify genes that increase the likelihood of developing nicotine dependence.

\section{The fate of Fisher's sceptical hypothesis}

How has Fisher's hypothesis about genetics of smoking and lung cancer fared in the light of recent genetic research? Research has partially supported Fisher's hypothesis in finding a substantial genetic component to smoking initiation and persistence. There is also some support for the hypothesis that genetic factors play a role in diseases caused by smoking, such as cancers generally $y^{50}$ and lung cancer in particular, ${ }^{5253}$ heart disease, ${ }^{54}$ and chronic obstructive lung disease. ${ }^{55}$

However, this genetic research has also undermined the limited plausibility Fisher's hypothesis ever had (which was never very strong when it was first proposed; see the 1964 US General Surgeon's report on Smoking and health, ${ }^{56}$ pages 193-6). The main reason is that the genes that increase the risks of smoking (for example, genes that regulate nicotine dependence and the dopamine system) are different from those that increase the risk of lung cancer (for example, genes that affect the metabolism of carcinogens in tobacco smoke). This is contrary to Fisher's hypothesis which required that the same genes caused both smoking and lung cancer. An improved understanding of the biological mechanisms of carcinogenesis and cardiovascular disease is also beginning to provide detailed explanations of the strong associations observed between cigarette smoking and these diseases (for example, Humphries and colleagues ${ }^{54}$ ). Genetic research on smoking has therefore made Fisher's sceptical position on cigarette smoking and lung cancer no more scientifically credible than creation science. ${ }^{57}$

\section{POLICY IMPLICATIONS}

\section{Predictive genetic testing for nicotine dependence}

Technological optimists ${ }^{58}$ have argued that the molecular mapping of the human genome will allow genetic screening of the population to identify persons at high risk of developing specific diseases-for example, cancers and heart disease. These high risk individuals can then be given appropriate behavioural and pharmacological interventions to prevent these diseases from occurring. This has been described as "predictive genetic testing". ${ }^{59}$ What are the prospects for predictive screening to identify those at risk of nicotine addiction? 
Table 2 Hypothetical distribution of susceptibility genes in the population, each with a prevalence of $10 \%$ and each carrying a relative risk of disease of 3.0.

\begin{tabular}{llccc}
\hline & \multicolumn{3}{l}{ Gene combination } \\
\cline { 2 - 5 } & None & Any one & Any two & All three \\
\hline $\begin{array}{l}\text { Percentage of } \\
\text { population }\end{array}$ & 72.9 & 24.3 & 2.7 & 0.1 \\
Relative risk & 1.0 & 3.0 & 9.0 & 27.0 \\
\hline
\end{tabular}

There is one compelling reason why we would not be interested in predictive testing for nicotine dependence: there is no public health interest in encouraging people to smoke tobacco, regardless of their risks of nicotine dependence. Even if this were not true, there are other good reasons why it would not be good policy to screen for susceptibility to nicotine dependence. $^{59}$

Firstly, predictive testing is most defensible when we screen for disorders in which a single gene confers a high risk of developing a serious life threatening disease and when safe and effective interventions exist. ${ }^{60}$ When multiple genes and multiple environmental risk factors predispose to common diseases, there may be gene-gene or gene-environment interactions, with the result that these genes are "incompletely penetrant" - that is, a person with these genes has an increased risk of developing the disease but the absolute probability of their doing is often still quite small. ${ }^{59}$ In general, the more genes that are involved in disease susceptibility, the less useful to individuals is information about their genotype. Some simple calculations show that there do not have to be many genes involved for this to be true.

Let us assume: ( 1 ) that there are three genes, each of which trebles the risk of nicotine dependence (a relative risk of 3); (2) that each has a frequency of $10 \%$ in the population; (3) that the genes are inherited independently; and (4) that their risks are multiplicative. There would be 8 possible combinations of genotypes with the prevalences and relative risks shown in table 2. Most people (72.9\% of the population) would not have any increased risk. Almost a quarter (24.3\%) would have a modest threefold increase in risk. The group with a ninefold increase in risk would comprise $2.7 \%$ of the population, and only $0.01 \%$ of the population would have the highest risk, a 27-fold increase in risk.

Secondly, given the low prevalence of high risk combinations of susceptibility genes, a very large number of individuals would need to be screened to identify those with these genes. This is expensive and difficult to justify on public health grounds. ${ }^{61}{ }^{62}$

Thirdly, screening is only justifiable if there is an effective intervention to prevent the disorder in those who possess susceptibility genes. ${ }^{59}$ "Avoid smoking" is good advice regardless of one's genotype for nicotine dependence. The development of an effective nicotine vaccine ${ }^{63}$ would provide more incentive for screening. But such screening would also raise a different ethical issue (for example, about the right of parents to vaccinate their children). It would also raise serious questions of public policy-for example, would it be more practicable to screen and vaccinate or simply to have universal nicotine vaccination? Who would pay the costs of such a programme? How likely is it that such a programme would be publicly funded in the face of tobacco industry opposition?

Fourthly, there is a possibility that predictive genetic testing may also have perverse and unintended effects. For example, what effects would testing adolescents for susceptibility to nicotine have on their preparedness to try smoking? What effects would it have on health insurance and on the social stigmatisation of those who are at risk?

\section{Predictive genetic testing for tobacco related diseases}

The tobacco industry is much more likely to be interested in screening for genes that increase a smoker's susceptibility to smoking related diseases. Its executives may hope that the identification of susceptibility genes for tobacco related diseases would enable individuals who lacked these genes to smoke tobacco "safely" ${ }^{64}$ This proposal is even more impractical from a public health perspective than screening for susceptibility to nicotine dependence, for several reasons.

Firstly, there is a major problem in making predictions about disease risks for individuals when, as seems likely, multiple genes are involved in disease susceptibility. Secondly, cigarette smoking also causes multiple diseases, with lung and other cancers, heart disease, and chronic obstructive lung disease being the most prevalent. Thirdly, the combination of multiple susceptibility genes and multiple diseases means that all smokers will have at least one susceptibility gene for one or more smoking related diseases. ${ }^{64}$ The impracticality of such screening may not prevent the tobacco industry from using the possibility of this type of screening to reassure ambivalent smokers that they can continue to smoke. Public health professionals will therefore need to be well versed in explaining its impracticality.

\section{Better treatment of nicotine dependence}

The most likely benefit of research on the genetics of smoking is an improvement in smoking cessation rates. ${ }^{46}$ The need to improve smoking cessation rates will increase because, as the population prevalence of smoking declines, the proportion of smokers with multiple genetic predispositions to nicotine dependence will probably increase, as will the proportion of smokers with co-morbid mental health problems that make it difficult to quit. ${ }^{65}$ Genetic research on smoking may improve the success of smoking cessation in a number of ways.

Firstly, a better understanding of nicotine dependence may lead to the development of more effective smoking cessation drugs. These may include drugs that act on key neural reward pathways and affect nicotine metabolism. These drugs may have fewer adverse side effects than existing ones. There may also be nicotine vaccines to help ex-smokers remain abstinent by preventing nicotine from acting in the brain..$^{63}$

Secondly, genotyping of smokers desiring help with cessation may better match patients to existing cessation drugs such as, bupropion (Zyban; GlaxoSmithKline), nortriptyline, and nicotine replacement. ${ }^{46}$ If, as seems likely, the prediction of treatment response from individual genes is modest, actuarial methods (such as multiple regression) will be needed. Given the expense of genotyping (even with a reduction in cost with technological improvements), "nicotine pharmacogenomics" will need to improve upon treatment matching using smoking behaviour (for example, the Fagerstrom scale or number of previous unsuccessful quit attempts) and on a policy of not matching by offering all patients the treatment that, averaged across genotypes, is most effective.

We will also need to consider disadvantages of giving smokers information about their genetic vulnerability to nicotine dependence. Will it, for example, encourage smokers to believe that their nicotine dependence is intractable ${ }^{66}$ We will need to provide better education about the implications of genetic information to overcome the mistaken belief that genetic causation of behaviour means that it cannot be changed. We need to use easily understood examples, such as "spectacles can correct shortsightedness even though it is under partial genetic control".

\section{Implications for smoking control policies}

Smoking control policies aim to reduce the availability of tobacco by making it expensive by imposing high taxes on tobacco products and by restricting minors' access to tobacco. ${ }^{67}$ These policies affect the whole community, not just 
those who are at risk of nicotine dependence. One can expect the tobacco industry to argue that on the grounds of efficiency and equity tobacco control measures should be focused on those at highest risk of becoming nicotine dependent.

There are a number of problems with this superficially attractive argument. Firstly, when multiple genes are implicated in nicotine dependence it is impractical to identify the small number of individuals at highest risk, as argued above. Secondly, population screening for nicotine dependence susceptibility genes is much more expensive than simply taxing tobacco use, protecting minors, and not allowing tobacco promotion. Thirdly, one does not need to be nicotine dependent to experience adverse health effects from smoking. Hence, the prevention of nicotine dependence will not prevent other smoking related diseases.

One can also anticipate the argument that individuals should be given a choice as to whether they undergo genetic screening for susceptibility to tobacco related disease. If one accepts this argument, then the wealthy may choose to be tested. There would be no case, however, for government funding or private health insurance coverage for such screening. The tobacco industry may consider funding such screening programmes as a potentially useful way of encouraging smokers to believe that they can reduce the risks of continuing to smoke.

The tobacco industry has lately developed other interests in biotechnology. Japan Tobacco has entered into an agreement with a US biotechnology company to develop and license a vaccine against lung cancer. ${ }^{68}$ Presumably the intention is to offer the vaccine to smokers who want to continue to smoke so that they can reduce their chances of developing lung cancer.

There are a number of major objections to this proposal, even if we ignore the considerable uncertainty about how effective a vaccine will be in preventing lung cancer in smokers. Firstly, it is arguably unethical for tobacco companies to profit from preventing a disease of which their product is the major cause. ${ }^{68}$ Secondly, because lung cancer is only one of 50 diseases that cigarette smoking causes, reducing this risk will not eliminate the health risks of cigarette smoking.

\section{CONCLUSIONS}

Twin, adoption, and other studies suggest that all stages of tobacco use and dependence are partially under genetic control. A number of candidate genes have been identified to explain this association but none have so far been consistently replicated. This reflects technical difficulties in doing association studies with a behaviour like smoking that is probably influenced by multiple genetic factors.

Research on the genetics of smoking has increased our understanding of nicotine dependence and it is likely to illuminate the mechanisms by which cigarette smoking adversely effects the health of smokers. Genetic research has undermined Fisher's hypothesis that there is a common genetic cause for cigarette smoking and lung cancer.

The most immediate benefit of work on the genetics of smoking from a tobacco control perspective may be more effective drugs to assist smokers to stop smoking. It may allow better matching of smokers to cessation treatments. Population screening for genes that confer susceptibility to nicotine dependence or smoking related diseases is unlikely to be practical.

Improved understanding of the genetics of smoking are not likely to affect public health tobacco control policies. It is much simpler, cheaper, and more efficient to discourage the whole population from smoking tobacco than it is to attempt to make smoking safer by identifying those at highest risk of nicotine addiction or smoking related disease.

The tobacco industry can be expected to use whatever opportunities genetics and biotechnology of smoking and smoking related disease provide to ensure the longevity of their industry. Public health advocates would therefore be wise to keep abreast of developments in the genetics of smoking and biomedical innovations in treating smoking related diseases.

\section{ACKNOWLEDGEMENTS}

Supported by NIH grants DA12540, DAl2854 (PAFM) from the National Institute on Drug Abuse and AA07728(ML) from the National Institute on Alcohol Abuse and Alcoholism. The authors would like to thank Andrew Heath for helpful comments on an earlier draft of this paper.

\section{Authors' affiliations}

W Hall, Office of Public Policy and Ethics, Institute for Molecular Bioscience, University of Queensland, St Lucia, Queensland 4072,

Australia

P Madden, M Lynskey, Missouri Alcoholism Research Center,

Department of Psychiatry, Washington University School of Medicine, 40

N Kingshighway, Suite One, St Louis, MO 63108, USA

\section{REFERENCES}

1 Kozlowski LT. Rehabilitating a genetic perspective in the study of tobacco and alcohol use. Br J Addiction 1991;86:517-20.

2 Stolley PD. When genius errs: R.A. Fisher and the lung cancer controversy. Am J Epidemiol 1991;133:416-25.

3 Fisher RA. Cigarettes, cancer and statistics. Centennial Review 1958;2:151-66.

4 Niu T, Chen C, Ni J, et al. Nicotine dependence and its familia aggregation in Chinese. Int J Epidemiol 2000;29:248-52.

5 Eaves LJ, Eysenck HJ. The genetics of smoking. In: Eysenck HJ, ed. The causes and effects of smoking. London: Temple-Smith, 1980.

6 Osler M, Holst C, Prescott E, et al. Influence of genes and environment on adult smoking behavior assessed in an adoption study. Genet Epidemiol 2001;21:193-200.

7 Rutter M, Pickles A, Murray R, et al. Testing hypotheses on specific environmental causal effects on behavior. Psychol Bull 2001; 127:291-324

8 Heath AC, Madden PAF. Genetic influences on smoking behavior. In Turner JR, Cardon LR, Hewitt JK, eds. Behavior genetic approaches in behavioral medicine. New York: Plenum Press, 1995:45-66.

9 Medlund P, Cederlof R, Floderus-Myrhed R, et al. A new Swedish twin registry. Acta Med Scand 1977; supplementum 600.

10 Raaschou-Nielsen E. Smoking habits in twins. Danish Medical Bulletin 1960;7:82-8.

11 Kaprio J, Sarna S, Koskenvuo M, et al. The Finnish twin registry: baseline characteristics. Section II. Helsinki: University of Helsinki Press, 1978.

12 Heath AC, Cates RC, Martin NG, et al. Genetic contribution to risk of smoking initiation: comparisons across birth cohort and across cultures. Journal of Substance Abuse 1993;5:221-46.

13 Madden PAF, Heath AC, Bucholz KK, et al. Genetics and smoking. Paper presented at the 55th annual meeting of the College on Problems of Drug Dependence. Toronto, Canada, 12-17 June 1993.

14 Carmelli D, Swan GE, Robinette D, et al. Genetic influence on smoking - a study of male twins. N Engl J Med 1992;327:881-3.

15 True WR, Heath AC, Scherrer JF, et al. Genetic and environmental contributions to smoking. Addiction 1997;92:1277-87.

16 Kaprio J, Koskenvuo M. A prospective study of psychological and socio-economic characteristics, health behavior and morbidity in cigarette smokers prior to quitting compared to persistent smokers and non-smokers. J Clin Epidemiol 1988;41:139-50.

17 Heath AC, Martin NG. Genetic models for the natural history of smoking: evidence for a genetic influence on smoking persistence. Addict Behav 1993;18:19-34

18 Heath AC. Persist or quit? Testing for a genetic contribution to smoking persistence. Acta Genet Med Gemellol (Roma) 1990;39:447-58

19 Madden PAF, Heath AC, Pedersen NL, et al The genetics of smoking persistence in men and women: a multicultural study. Behav Genet 1999:29:423-31.

20 Prescott CA, Kendler KS. Genetic and environmental influences on alcohol and tobacco dependence among women. In: JB Fertig, JP Allen, eds. Alcohol and tobacco: from basic science to clinical practice. National Institute on Alcohol Abuse and Alcoholism Research, Monograph No. 30 Bethesda, Maryland: NIAA, 1995:59-87.

21 True WR, Xian H, Scherrer JF, et al. Common genetic vulnerability for nicotine and alcohol dependence. Arch Gen Psychiatry 1999;56:655-61

22 Kendler, KS, Neale MC, Sullivan P, et al. A population-based twin study in women of smoking initiation and nicotine dependence. Psychol Med 1999:29:299-308

23 Kendler KS, Neale MC, Kessler RC, et al. A test of the equal environment assumption in twin studies of psychiatric illness. Behav Gen 1993;23:21-7.

24 Kendler KS, Neale MC, Kessler RC, et al. Parental treatment and the equal environment assumption in twin studies of psychiatric illness. Psychol Med 1994;24:579-90. 
25 Kendler KS, Gardner CO. Twin studies of adult psychiatric and substance dependence disorders: are they biased by differences in the environmental experiences of monozygotic and dizygotic twins in childhood and adolescence? Psychol Med 1998;28:625-33.

26 Kendler KS, Heath AC, Neale MC, et al. A population-based twin study of alcoholism in women. JAMA 1992;268:1877-82.

27 Lynskey MT, Heath AC, Nelson EC, et al. Genetic and environmental contributions to cannabis dependence in a national young adult twin sample. Psychol Med (in press).

28 Kaprio J, Koskenvuo M, Langinvainio $\mathrm{H}$, et al. Genetic influences on use and abuse of alcohol: a study of 5638 adult Finnish twin brothers. Alcoholism: Clinical and experimental Research 1987; 1 1:349-56.

29 Heath AC, Kendler KS, Eaves L, et al. The resolution of biological and cultural inheritance: Informativeness of different relationships. Behav Genet 1985:23:29-50.

30 Shields J. Monozygotic twins brought up apart and brought up together London: Oxford University Press, 1962.

31 Kaprio J, Koskenvuo M, Langinvainio H. Finnish twins reared apart, IV: smoking and drinking habits: a preliminary analysis of the effect of heredity and environment. Acta Genet Med Gemellol (Roma) $1984: 33: 425-33$.

32 Kendler KS, Thornton LM, Pedersen NL. Tobacco consumption in Swedish twins reared apart and reared together. Arch Gen Psychiatry 2000;57:886-92.

33 International Human Genome Sequencing Consortium. Initial sequencing and analysis of the human genome. Nature 2001;409:860-921.

34 Pomerleau OF. Individual differences in sensitivity to nicotine: implications for genetic research on nicotine dependence. Behav Genet 1995;25:161-77.

35 Long JC, Knowler WC, Hanson RL, et al. Evidence for genetic linkage to alcohol dependence on chromosomes 4 and 11 from an autosome-wide scan in an American Indian population. Am J Med Genet 1998;81:216-21.

36 Reich T, Edenberg HJ, Goate A, et al. Genome-wide search for genes affecting the risk for alcohol dependence. Am J Med Genet 1998;81:207-15.

37 Vallejo RL, Wilhelm LA, Hoopes D, et al. Genome wide search for genes affecting vulnerability to alcohol dependence in Finnish pedigrees. Am J Human Genet 1998:63:A45.

38 Ott J. Analysis of human genetic linkage, revised ed. Baltimore: Johns Hopkins University Press, 1991.

39 Lander E, Schork NJ. Genetic dissection of complex traits. Science 1994;265:2037-48

40 Risch N. Linkage strategies for genetically complex traits. II. The power of affected relative pairs. Am J Human Genet 1990;46:229-41.

41 Bishop DT, Williamson JA. The power of identity-by-state methods for linkage analysis. Am J Human Genet 1990;46:254-65.

42 Pianezza ML, Sellers EM, Tyndale RF. Nicotine metabolism defect reduces smoking. Nature 1998;393:750.

43 Oscarson M, Gullsten H, Rautio A, et al. Genotyping of human cytochrome P450 2A6 (CYP2A6), a nicotine C-oxidase. FEBS Letters 1998;438:201-5.

44 Lerman C, Caporaso NE, Audrain J, et al. Evidence suggesting the role of specific genetic factors in cigarette smoking. Health Psychol 1999:18:14-20.

45 Batra A, Gelfort G, Bartels M, et al. The dopamine D2 receptor (DRD2) gene - a genetic risk factor in heavy smoking? Addict Biol 2000;5:429-36.
46 Walton R, Johnstone E, Munafo M, et al. Genetic clues to the molecular basis of tobacco addiction and progress towards personalised therapy. Trends in Molecular Medicine $2001 ; 7: 70-6$

47 Munafo $M$, Johnstone $E$, Murphy $M$, et al. New directions in the genetic mechanisms underlying nicotine addiction. Addict Biol 2001;6:109-17.

48 Swan GE. Implications of genetic epidemiology for the prevention of tobacco use. Nicotine and Tobacco Research 1999;1:S49-56.

49 Risch N. Mapping genes for psychiatric disorders. In Gershon ES Cloninger CR, eds. Genetic approaches to mental disorders. Washington DC:American Psychopathological Association, 1994.

50 Lichtenstein P, Holm NV, Versalko PK, et al. Environmental and heritable factors in the causation of cancer: analyses of cohorts of twins from Sweden, Denmark and Finland. N Engl J Med 2000;343:78-85.

51 Risch N. The genetic epidemiology of cancer: interpreting family and twin studies and their implications for molecular genetic approaches. Cancer Epidemiology, Biomarkers and Prevention 2001;10:733-41.

52 Bouchardy C, Benhamou S, Journekova N, et al. Metabolic genetic polymorphisms and susceptibility to lung cancer. Lung Cancer 2000;32:109-12.

53 Devereux TR, Taylor JA, Barret JC. Molecular mechanisms of lung cancer: interaction of environmental and genetic factors. Chest 1996;109:14S-19S.

54 Humphries SE, Talmud PJ, Hawe E, et al. Apolipoprotein E4 and coronary heart disease in middle-aged men who smoke: a prospective study. Lancet 2001;358:1 15-19.

55 Lomas DA, Silverman EK. The genetics of chronic obstructive pulmonary disease. Respiratory Research $2001 ; 2: 20-6$.

56 US Department of Health, Education, and Welfare. Smoking and health. Report of the Advisory Committee to the Surgeon General of the Public Health Service. Washington, DC: Public Health Service, 1964. (PHS Publication No. 1103.)

57 Kitcher P. Abusing science: the case against creationism. Cambridge, Massachusetts: MIT Press, 1983.

58 Collins FS. Shattuck lecture: medical and social consequences of the Human Genome Project. N Engl J Med 1999;341:28-37.

59 Evans JP, Skrzynia C, Burke W. The complexities of predictive genetic testing. BM 2001;322:1052-6.

60 Holtzman NA, Marteau TM. Will genetics revolutionise medicine? N Engl J Med 2000;343:141-4.

61 Holtzman NA, Shapiro D. Genetic testing and public policy. BM 1998;316:852-6.

62 Vineis $\mathbf{P}$, Schulte $\mathrm{P}$, McMichael AJ. Misconceptions about the use of genetic tests in populations. Lancet $2001 ; 357: 709-12$

63 Shine B. Nicotine vaccine moves toward clinical trials. NIDA Notes 2000;15:(5): 1-2.

64 Wang XL, Mahaney MC. Geneotype-specific effects of smoking on risk of CHD. Lancet $2001 ; 358 ; 87-8$.

65 Degenhardt L, Hall W. The relationship between tobacco use, substance-use disorders and mental health: results from the national survey of mental health and well-being. Nicotine and Tobacco Research $2001 ; 3: 225-34$

66 Marteau TM, Croyle RT. Psychological responses to genetic testing. BM 1998;316:693-6.

67 World Health Organization. Guidelines for controlling and monitoring the tobacco epidemic. Genetics: World Health Organization, 1998.

68 Genewatch UK. Patent on life warning as links between Biotech companies and Japan Tobacco exposed. Access date 13 November 2001. URL: http://www.genewatch.org/press\%20 Releases/pr20.htm/ 